\title{
Application of ICT in the Online Education of Apparel Design and Production within the framework of ICT-TEX project
}

\author{
Hassan Saeed ${ }^{1}$, Yordan $\mathrm{Kyosev}^{1}$, Radka Atanasova ${ }^{2}$, Angel Terziev², and Carla Hertleer ${ }^{3}$ \\ ${ }^{1}$ Technische Universität Dresden, Institute of Textile Machinery and High-Performance Material \\ Technology (ITM), Dresden, Germany \\ ${ }^{2}$ Technical University of Sofia, Faculty of Power Engineering and Power Machines, Sofia,Bulgaria \\ ${ }^{3}$ AUTEX/ Ghent University, Zwijnaarde, Belgium
}

\begin{abstract}
One of the key lessons learned during the pandemic of COVID19 is that the digital education and adaptation of Information and Communication Technologies (ICT) should not be viewed as an island on its own but should be considered as an integral part of all education and training. The ICT-TEX project is an EU-funded project which aims to integrate ICT in online education of textile and clothing. Within the framework of this project, deficiency areas have been identified with a comprehensive survey conducted across the project partner countries. A new course curriculum has been developed based on desk research, field research, surveys, and Gap Analysis. Eight modules (around 16 courses) according to the needs of the textile and clothing industry (TCI) will be developed within the framework of the project. This paper discusses the methodology of applying ICT in new course content for Apparel Design and Production which is a pilot course and serves as a benchmark for further development of other courses.
\end{abstract}

\section{Introduction}

The textile industry is a traditional and leading industrial sector in Europe with around 160.000 companies, mostly small and medium-sized niche players [1]. They produce highquality and innovative products and focus on creativity and outstanding customer service. Therefore, the next generation textile industry workers must be well educated and have the required competencies and skills. The ICT-TEX (ICT in Textile and Clothing Higher Education and Business) project presented in this paper, is an Erasmus+ Knowledge Alliance aiming to improve the competencies in Information Communication Technology (ICT) for people working in the field of the Textile and Clothing Industry (TCI). This is done by developing syllabuses for various textile subareas that will be provided through an online platform on the project website and made available to all interested parties. 


\section{Methods and Results}

\subsection{The ICT-TEX project in general}

The ICT-TEX project is an Erasmus + Knowledge Alliance, an EU program aiming to strengthen Europe's innovation capacity and foster innovation in higher education by setting up transnational and result-driven activities between higher education institutions and businesses. In this ICT-TEX project, 12 geographically spread partners collaborate to achieve this goal, forming a balanced group of universities, companies, and non-profit organizations active in the textiles and clothing areas. The Project Coordinator is the Technical University of Sofia, Faculty of Power Engineering and Power Machines, Bulgaria. The project commenced on 1 January 2020 and will run for 3 years.

ICT technologies such as CAD, CAM, CAE, and PLM systems have developed more and more admission into the Textile and Clothing Industry, thus requiring personnel with a higher level of ICT skills is becoming important than before. The project aims at developing a curriculum of 'Information Technology in Design of Textile and Clothing' to improve the knowledge and skills of students, teachers, and staff. At first, the current situation was evaluated by distributing a survey amongst companies in Europe to determine the needs and requirements in terms of ICT and entrepreneurial skills. At the next stage, a gap analysis was performed from survey results and desk analysis to get a clear view of what is required. These insights were used to develop an adapted curriculum. The areas dealt with within the project are Design and Production of Knitwear; Design \& Production of Woven Fabrics; Design \& Production of Technical and Intelligent Textiles; Industrial Engineering, Quality Control \& Management, and Finishing, Printing \& Functionalization. After that, the pilot syllabuses are developed for Entrepreneurship, ICT - Digital Skills, and Apparel Design \& Production. The last-mentioned module will be extensively described in this paper.

\subsection{Preliminary work on the pilot Module of Apparel Design and Production}

The TCI companies of the EU are facing a shortage of experts in their fields. Therefore, developing necessary competencies and skills for the existing workforce and attracting qualified young experts of the next generation has become a priority for these companies. The textile industry is in pressing need of human resources because a great part (about $40 \%$ ) is expected to retire in the next few years, and it is not attractive to young people who prefer ICT in general but are not aware that ICT is widely applied in the textile industry [1].

To design a new course curriculum and its content, two research approaches were adopted to understand the need for Apparel Design and Production. During the first approach called 'desk research' led by TU Dresden, the changes and needs of industry were studied and changes taking place in apparel design and production were researched. During the second approach of 'field research', a comprehensive survey questionnaire was developed by the mutual collaboration of consortium to understand the needs of TCI.

\subsubsection{Desk Research}

Due to changing policies of the EU, UN policies for environmental protection, corporate social responsibility for sustainable development, the technology has continuously developed for TCI businesses. To understand the state of the art and innovative character of Apparel Design and Production, an analysis of the subject area is performed. Clothing production has doubled in the last two decades, driven by the growing 
middle-class population across the globe and due to fast fashion [3][4]. Due to quicker style changes and an increased number of collections per year and often at a lower price, the clothing industry is showing growth in terms of sales. The technological process of conventional apparel design and production processes can be divided mainly into two parts. The first one is the design part and the second involves the production of clothing.

\subsubsection{Apparel Design}

Applications of CAD/CAM made their first appearance in the clothing cutting room in the 1970s. Nowadays interactive garment CAD techniques provide garment enterprises with fashion design, pattern making, pattern grading, and marker making. Compared to manual operations, the techniques automate repetitive time-consuming tasks, shorten the product development cycle, improve product quality and respond more quickly to the customer's market, thus the techniques are widely utilized and play a significant role in mass production in the apparel industry [5].

Pattern making is the art of designing patterns by making templates from which clothing and industrial items can be sewn. A pattern making process realizes the imagination of the designer from sketching to the real product. Pattern makers are also called "Technical Designers". The aesthetic appearance, correct fit, and drape attributes of a garment depend significantly on garment-making process. Pattern making is considered the first step in garment production [6]. While making a garment as per design, production patterns are used to trace the various garment parts onto fabric before cutting and assembling. The digital pattern developing process has two paths. One path develops apparel according to traditional 2D pattern making technology [7]. There are three methods: parametric design, traditional grading technique, and pattern generating based on artificial intelligence. Another path develops patterns through surface flattening directly from an individual 3D apparel model. Applying this parametric method can largely improve the efficiency of pattern design or pattern alteration.

Traditional sample creation involves time-consuming manual fittings and re-fittings [8]. With the advancements in virtual reality applications, the garment industry has strived for new developments. 3D virtual try-on brings a whole new level of efficiency to the design department by combining the latest in 3D rendering technology with powerful, proven pattern production software. A large range of techniques is selected and organized into several key modules (digital human modelling, 3D garment design and modification, numerical integration of draping, 2D pattern generation, geometric details modelling, parallel computation, and GPU acceleration) which form the core of a 3D garment design technology platform [9].

The clothing industry increasingly prefers to use computer-aided design (CAD) techniques for both fashion design and pattern creation as it offers greater efficiency and time-saving solutions to many complicated tasks as well as facilitating Internet-based communication amongst designers, manufactures, and retailers. Specialized 2D CAD software, including packages such as cad.assyst (Assyst), Modaris (Lectra), Accumark 2D (Gerber), PDS 2D (Optitex), Master Pattern Design (PAD System), TUKAcad (Tukatech), GRAFIS (Software Dr. K. Friedrich), AudacesApparel (Audaces), COAT (COAT- EDVSysteme) and Fashion CAD (Cad Cam Solutions), support geometrical pattern drafting from first principles using only anthropometric measurements of the target size and shape. In today's apparel industry, the designs are generally made in digital form with the help of CAD software [5].

The most advanced 3D applications available today combine patterns with fabric physical properties, appearance, and stitching lines to simulate how the fabric will fall or drape in form of a garment. 3D body scanning machines take all the millions of points of a company's 
fit model to create an avatar of the same body, which can then be used to accurately predict the ease and tightness of a garment [2].

The user can then adjust the pattern pieces in the 2D pattern making application and view them in the 3D application to re-simulate and once again check the fit. These modifications are easily transferred to paper patterns for fine-tuning. Today's 3D applications include automatic functions specifically designed to allow trained technical designers to adjust 2D patterns [10]. To check if the fit of the pattern is correct, the prototyping on that basis is done to check if the product is suitable for bulk production. It is usually an iterative work, which is performed until the desired results are achieved. An increasingly used alternative is the 3D fit simulation where the fabric properties are given to material in a software environment and 2D patterns are digitally sewn and draped on an avatar. In this way, the prototyping work is reduced to save time and resources. Modern 3D CAD software also offers 3D visualization during motion which makes the product realization even more realistic during the design phase [9]. There are several 3D CAD solutions providers in the market, but Clo3D, Modaris v8, Tuka3D, and 3D Vidya are mostly used.

\subsubsection{Apparel Production}

The apparel production starts from getting prepared for cutting the fabric layers in required pattern. The process of cutting starts from the lay planning for cutting. The cutting lay plan or commonly known as a marker is generated in a way that maximum efficiency of fabric lay is achieved to reduce the fabric wastage as much as possible. This cutting lay planning is carried out in combination with 2D CAD software which was prior used to design pattern pieces. The cutting is performed either manually or computerized in apparel production. The efficiency and accuracy of computerized cutting are much more than manual cutting. The use of manual or computerized technologies depends on factors like required garment production, the complexity of cut parts, type of material, labor costs and return on investment of technology acquisition. The sewing department in apparel production involves most of human resources than any other department of clothing production. There are three main production systems in practice in apparel production known as progressive bundle system, unit production system, and modular production system. The selection of production system used in apparel manufacturing is depending upon the type of garments produced and the investment made into the process. Digitalization is pushing towards the unit production system because it provides real-time information of production flow.

Types of sewing machines in sewing production depend upon the type of product being produced and its functional requirements. Automatic sewing operations are performed in the sewing industry for the reproducibility of sewing operations to realize mass production. These sewing machine automations are usually performed on operations like Pocket setter, Pattern seamer, Bartacks machines, Buttonholes machines, J-stitch (on zipper fly), Leather patches seamers, Belt Loop attaching machines, etc. In sewing production, the machine features like needle positioning during and after sewing operation, automatic thread trimmers, and the location of sewing at the seam start and end are also important for production efficiency, because it can facilitate the sewing operator by reducing work fatigues and also reduce the later work during apparel finishing. Sewing machinery manufacturers are presenting their concepts sewing stations using a universal robot working with a machine operator side by side and feeding multiple machines [11]. This is a tendency that can be observed in the future due to decreasing prices of robot technology and increasing labor costs.

The use of ICT in the clothing industry is taking importance with passing time. To keep the sewing production line in full view of managers and production supervisors, German sewing machine manufacturer Dürkopp Adler has presented its Qondac system, which keeps 
the record of each stage of the production stage and its efficiency in real-time and keep therecord of machine maintenance. The productivity of sewing machines and their status can be analyzed and machines can be maintained virtually. The interface can be connected with the ERP system of the organization e.g., SAP to exchange the status of production to other relative departments [12]

After the sewing has been finished, the garment goes to the finishing department where it is prepared for final shipment. The use of automatic universal finisher for shirts and pants is used to perform pressing. The use of simple pressing with steam function leaves burn/shiny marks on the fabric surface, which are more visible on fabrics with darker shades. With automatic finisher, different programs can be chosen according to the type of material and finish required. The digital database can be developed which can be retrieved, whenever the same material, fabric construction, material composition is processed in mass production. The company Veit GmbH is a market leader in finishing technology. Its Tunnel Finisher can replace manual tasks and improve production and labor costs [13]. Despite the advantages of automatic finishers on manual pressing, the comparison of the price is also important. A simple pressing station is way cheaper than the automatic finisher. Factors like labor cost and energy conservation are chosen while choosing between the technologies used.

\subsubsection{Field research (GAP Analysis)}

Understanding the educational needs in the future means knowing the current practices of the TCI business and respectively its historical background. The work has been done through desk analyses, historical evidence, and case studies in the past. Additionally, a preliminary questionnaire was prepared to provide appropriate business information for the analysis. Feedbacks from TCI enterprises were gathered. The GAP Analysis combined with the desk analysis served as the basis for the development of elaborated curriculum, syllabuses, and study materials.

The GAP analysis is essential for the implementation of the other work packages of the project too. In this way, the syllabuses and curriculum will meet the future needs of skilled and motivated workers for the TCI enterprises.

The GAP analysis was divided into three main stages:

- Description of the technological processes in the TCI enterprises: it was helpful to identify the difference between TCI product specialization, for instance: clothing, weaving, knitting, etc.

- Historical analysis of the technology changes in TCI enterprises: it allowed us to understand future steps in the development of the technology.

- Staff needs assessment: it defined the best employee and their current and future technological competencies, knowledge, and skills.

Some interesting results from the GAP Analysis regarding the course of "Apparel design and Production" are below. The detailed results are available online at the project website [14].

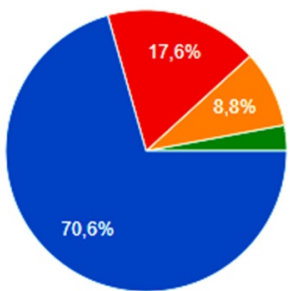

To fully develop the clothing patterns

Just to grade the details

Only to control and make small pattern changes

programmers knit

Fig. 1. What skills should patternmakers have in your company? 

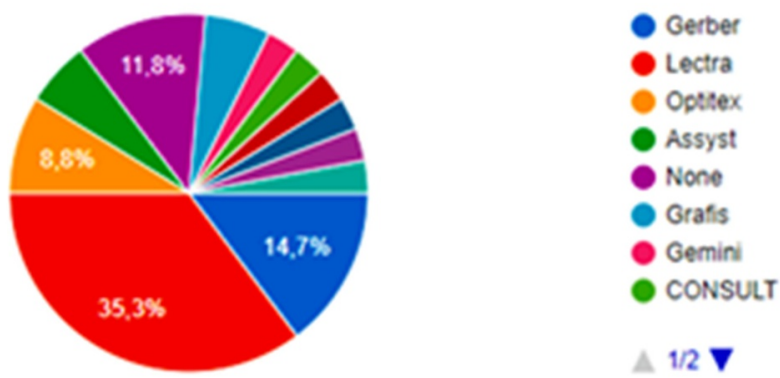

Fig. 2. What CAD systems do your company pattern makers work with?

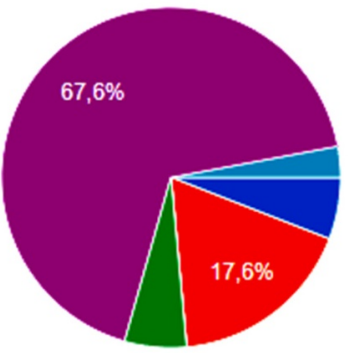

AccuMark3D

Modaris 3D

Morgan 3Dress

3D Vidya

None

Audeces

Fig. 3. What 3D Visualization and Fit accuracy software does your company use?

The survey results provided an interesting insight into the general practices of the European clothing industry. For example, it can be seen from the survey results that more than $2 / 3^{\text {rd }}$ of participants said that they do not use any sort of $3 \mathrm{D}$ CAD software for visualization and fit simulation at all. This is a very interesting finding that also shows great room for improvement. The $3 \mathrm{D}$ visualization and fit simulation can reduce the iterative product prototyping procedure and reduce the lead times from product realization to product manufacturing.

Based on GAP Analysis conducted there is following skills need assessment for the use of ICT in general:

- To operate with advanced/automated production systems; to manage integrated systems for the exchange of information between different production processes also integrating internet of things; to improve the integration level of CAD/CAM and ERP systems;

- Knowledge and ability to apply and manage:

- $\quad$ Radio Frequency ID (RFID) task;

- Sensors and Internet of Things coupled with new software;

- $\quad$ Augmented Virtual Reality (AVR);

- Block-chains and Artificial Intelligence.

- Ability to use ERP systems to better manage production planning and control, supply chain, logistics, costumers' relationships, workloads, and work distribution, environmental impact, quality;

- Ability to use advanced design software, i.e., software able to detect contours and body shapes for tailor-making designs; 
- $\quad$ Ability to use specialized software and analyze big data to study current market trends and predicts the future ones;

- Ability to use marketing techniques and tools to better targeting specific consumer categories and groups;

- Ability to use social media to engage and interact with customers and influence their buying behaviors.

\subsection{Overview and presentation of the syllabuses of courses of Apparel Design and Production}

Based on the desk research and field research results obtained through GAP analysis, the new course curriculum objectives were designed and a new course curriculum is developed. The course of Apparel Design and Production was subdivided into three main courses.

1. 2D CAD Pattern Making;

2. 3D CAD Simulation;

3. Apparel Production.

The details and objectives which are aimed to be achieved within the framework of the ICTTEX project are explained for each course.

\subsubsection{D CAD Pattern Making}

Today's clothing industry is moving toward using advanced technology in designing and pattern-drafting. Clothing companies continuously seek new solutions for saving time in product development and generally increasing efficiency in activities raging from, the design process through the manufacturing process. Such programs can enhance communication, ease flow, production, and cost-effectiveness at all stages. 2D CAD Pattern Making is a knowledge-intensive and creative course that will lead learners across different pattern making techniques taking into consideration materials, colors, and styles combination. Lessons are taught using specialized CAD software (AccuMark by Gerber Technology, Modaris by Lectra).

Following topics will be covered from the course of 2D CAD Pattern Making.

- Introduction to CAD functionalities

- Modelling techniques for different garments

- Symmetry and asymmetry principles

- Algorithms for pattern making of basic apparel constructions

- Computer grading of details

- Algorithms for pattern making of specific garment elements

- Design of gathered elements

\subsubsection{D CAD Simulation}

Three-dimensional (3D) virtual prototyping is getting increasingly important for apparel design. Based on the utilization of 3D CAD simulation, product development in the clothing industry becomes faster and faster. The integration of 3D CAD systems for garment design leads to higher accurate cloth fitting. During the course, the participants will be guided to create virtual garments from fashion design ideas analyzing the principal aspects of 3D simulation by using specific software.

The following topics will be covered from the course of 3D CAD simulation.

- Introduction of 3D simulation; 
- $\quad$ Virtual fit simulation in CLO 3D;

- $\quad 3 \mathrm{D}$ virtual model.

\subsubsection{ICT in Apparel Production}

The garment industry invariably goes through short fashion cycles. To survive in the market, regular innovations in color, style, design, fabric, finish, and fit are needed. Automated machinery and IT solutions are keys in such a scenario. Automations for cutting, sewing, buttonholes, $\mathrm{CAD} / \mathrm{CAM}$ for pattern making, etc., have brought down the cost of production considerably. Garment companies now focus on technology to be productive and costeffective at the same time, which means a skilled and constantly technically updated workforce. The course is focused on the analysis of the interconnections between innovative technologies and standard production processes to equip learners with relevant skills and knowledge.

Following topics will be covered from the course of ICT in Apparel Production:

- $\quad$ Sewing machines;

- $\quad$ Spreading/cutting;

- Finishing;

- Production systems;

- Automation in apparel production;

- Material management and work planning;

- Welding technologies.

\section{Conclusions}

A great deal of effort has been made to understand the needs of TCI businesses and HEI's have developed the new curriculum of different courses including Apparel Design and Production. The developed courses will cater to the needs of the staff of TCI businesses and will be freely available online on the project platform. Various interactivities have been developed where the learners will interact with the latest course content, with teachers, and with other learners and improve their online learning experience.

ICT-TEX is funded under the Erasmus + Program of the European Commission [Project Number:612248-EPP-1-2019-1-BG-EPPKA2-KA]. This publication reflects the views only of the author, and the Commission cannot be held responsible for any use which may be made of the information contained therein.

\section{References}

1. EURATEX, "Euratex annual report", June 2020.

2. Fibre2Fashion, "A glimpse of 3-D body scanning technology in the apparel industry," 2008. [Online]. Available: https://www.fibre2fashion.com/industry-article/2980/aglimpse-of-3-d-body-scanning-technology-in-the-apparel-industry.

3. Euromonitor International, "Euromonitor International Apparel \& Footwear (volume sales trends 2005-2015," 2016.

4. S. Herrmann, "A new textiles economy: redesigning fashion's future," Ellen MacArthur Foundation. p. 150, 2017.

5. Y. Xiu and Z.-K. Wan, "A survey on pattern making technologies in Garment CAD," in IEEE Conference Anthology, 2013, pp. 1-6, doi: 10.1109/ANTHOLOGY.2013.6784694. 
6. D. B. Datta and P. Seal, "Various approaches in pattern making for garment sector," Journal of Textile Engineering \& Fashion Technology, vol. 4, no. 1. 2018, doi: 10.15406/jteft.2018.04.00118.

7. H. Petrov, "Pattern Making of Clothing," TU Sofia, 2009.

8. Gerber Technologies, "Accumark-Next generation pattern design software for the fashion and apparel industry." [Online]. Available: https://www.gerbertechnology.com/fashion-apparel/design/accumark/.

9. Y.-J. Liu, D.-L. Zhang, and M. M.-F. Yuen, "A survey on CAD methods in 3D garment design," Comput. Ind., vol. 61, no. 6, pp. 576-593, 2010, doi: https://doi.org/10.1016/j.compind.2010.03.007.

10. Lectra, "What is Modaris." Anline]. Avale: https://www.lectra.com/en/products/modaris-expert.

11. M. Suh, "Automated Cutting \& Sewing Developments," 2020. [Online]. Available: https://www.textileworld.com/textile-world/features/2020/03/automated-cuttingsewing-developments/.

12. Dürkopp Adler GmbH, "The Digital Sewing Factory becomes reality." [Online]. Available: https:/www.duerkopp-adler.com/en/main/news/QONDAC.

13. Veit GmbH, "Tunnel Finisher 8657." [Online]. Available: https:/www.veit.de/en/products/tunnel-finisher/tunnel-finisher-veit-8657/.

14. V. Guagliumi, "Developing requirement of TCI technologies," 2020. 